УДК 536.22:62-437

\title{
WATER HEAT TRANSFER WITH TRANSVERSE FLOW PIPES AND TUBE BUNDLES
}

\author{
D. Sinat-Radchenko, N. Ivashchenko, S. Vasilenko \\ National University of Food Technologies
}

\begin{tabular}{|c|c|}
\hline Key words: & ABSTRACT \\
\hline $\begin{array}{l}\text { water, } \\
\text { pipes, } \\
\text { tube bundles, } \\
\text { transverse flow, } \\
\text { flow regimes, } \\
\text { heat transfer coefficient, } \\
\text { correction }\end{array}$ & $\begin{array}{l}\text { When water moves around the pipe, a boundary layer of } \\
\text { variable thickness is formed on the surface of the pipe by a fluid } \\
\text { stream. The change in the magnitude of the heat transfer coe- } \\
\text { fficient } \alpha\left(\mathrm{W} /\left(\mathrm{m}^{2} \cdot \mathrm{K}\right)\right) \text { along the circumference of the cylinder is } \\
\text { primarily determined by the nature of the fluid flow and the value } \\
\text { of the Reynolds number } \mathrm{Re}=\omega \mathrm{d} / \mathrm{v} \text {. The boundary layer turbu- } \\
\text { lence begins at } \mathrm{Re}>5 \text {. Heat transfer criteria equation for flow }\end{array}$ \\
\hline $\begin{array}{l}\quad \text { Article history: } \\
\text { Received 09.12.2019 } \\
\text { Received in revised form } \\
05.05 .2020 \\
\text { Accepted } 13.06 .2020\end{array}$ & $\begin{array}{l}\text { around pipes and tube bundles } \mathrm{Nu}=\mathrm{CRe}^{\mathrm{n}} \operatorname{Pr}^{\mathrm{m}} \Pi \varepsilon_{\mathrm{i}} \\
\text { Heat transfer depends on the initial turbulence flow substan- } \\
\text { tially. The flow turbulence is stabilized from the third row of the } \\
\text { tube bundle. The criterion equations for } \alpha \text { were obtained by sum- } \\
\text { marizing the experimental results for the third and subsequent }\end{array}$ \\
\hline $\begin{array}{l}\text { Corresponding author: } \\
\text { vinci@ukr.net }\end{array}$ & $\begin{array}{l}\text { tubular bundles. } \\
\text { The equations for calculating the heat transfer coefficients } \\
\text { include the thermo-physical properties of water. For the tempera- } \\
\text { ture range } 0 \ldots 130^{\circ} \mathrm{C} \text {, which is most used in the food industry, we } \\
\text { have obtained simple, accurate calculation formulas (the limit } \\
\text { relative error within one percent) for } \lambda, v \text {, Pr, etc. } \\
\text { We have proposed ready-made formulas for calculating water } \\
\text { heat transfer coefficients for different modes of transverse flow } \\
\text { in pipes and tube bundles. Numerical examples of calculation of } \\
\text { heat transfer coefficients are given. } \\
\text { In the same conditions } \alpha \text { in bunch in-line is higher than in } \\
\text { bunch staggered, where stagnant zones are formed in the pas- } \\
\text { sages between the rows of pipes. The results of the calculations } \\
\alpha \text { by the formulas we propose and the calculations } \alpha \text { through the } \\
\text { corresponding criterion equations coincide practically. Our me- } \\
\text { thod does not require the using any tables and interpolations. It } \\
\text { facilitates and accelerates the determination of the heat transfer } \\
\text { coefficient. It makes the determination of the heat transfer coe- } \\
\text { fficient simpler and faster. }\end{array}$ \\
\hline
\end{tabular}

DOI: $10.24263 / 2225-2916-2020-27-17$

(C) Д. С.Сінат-Радченко, Н .В. Іващенко, С. М. Василенко, 2020 


\title{
ТЕПЛОВІДДАЧА ВОДИ ЗА ПОПЕРЕЧНОГО ОБТІКАННЯ ТРУБ I ТРУБНИХ ПУЧКІВ
}

\author{
Д. Є. Сінат-Радченко, канд. техн. наук \\ Н. В. Іващенко, канд. техн. наук \\ С. М. Василенко, д-р техн. наук \\ Національний університет харчових технологій
}

На основі узагальнення даних з теплофрізичних властивостей води та аналізу ї тепловіддачі за поперечного обтікання труб і трубних пучків для інтервалу температур $0 \ldots 130^{\circ} \mathrm{C}$ і різних умов та режимів руху води запропоновано ряд простих, але досить точних фоормул і числових прикладів) для розрахунку коефріцієнтів тепловіддачі без використання будь-яких таблиць та інтерполяції. Це полегшує і прискорює інженерні розрахунки та дає змогу використовувати фрормули у різноманітних комп'ютерних програмах.

Ключові слова: вода, труби, пучки труб, поперечне обтікання, режими течії, коефіцієнти тепловіддачі, поправки

Постановка проблеми. Поперечне обтікання труб водою широко використовується в різноманітних теплообмінних апаратах. Для збільшення поверхні теплообміну труби збирають у пучки. Розміщення труб у пучках коридорне або шахове. Потік води може рухатись під різним кутом відносно осі труб. Розрахунки тепловіддачі в таких випадках складні і їх бажано та можна спростити.

Метою дослідження $\epsilon$ аналіз сучасного стану розрахунків тепловіддачі води за поперечного обтікання труб і трубних пучків та максимальне спрощення цих розрахунків.

Методи дослідження грунтуються на основі аналізу факторів, які впливають на величину коефіцієнта тепловіддачі за різних умов руху потоку води, узагальненні теплофізичних властивостей води простими розрахунковими формулами, опис формулами поправкових коефіцієнтів.

Результати досліджень. При обтіканні поодинокої труби потоком рідини на поверхні труби утворюється примежовий шар змінної товщини $\delta$.

Мінімальна товщина шару і відповідно максимальні значення коефіцієнта тепловіддачі $\alpha\left(\mathrm{BT} /\left(\mathrm{M}^{2} \cdot \mathrm{K}\right)\right)$ у лобовій точці. Далі $\delta$ поступово зростає, а в точці відриву промежовий шар відтісняється вихорами, які утворюються в кормовій частині течії $[1 ; 2]$.

Зміна $\alpha$ по окружності циліндра передусім визначається характером руху потоку рідини і величиною числа Рейнольдса $\mathrm{Re}=\omega \mathrm{d} / \nu$, де $\omega$ - швидкість потоку рідини в найвужчому перерізі каналу, м/c; d - зовнішній діаметр труби, м; vкінематична в'язкість рідини за ії середньої температури, м² $^{2}$. Турбулізація граничного шару починається при $\operatorname{Re}>5$.

Критеріальне рівняння тепловіддачі при обтіканні труб і трубних пучків для краплинних рідин має вигляд [3; 4]:

$$
\mathrm{Nu}=\mathrm{CRe}^{\mathrm{n}} \operatorname{Pr}^{\mathrm{m}} \Pi \varepsilon_{\mathrm{i}} .
$$

Тут шуканий критерій Нуссельта (в нього входить $\alpha$ ) $\mathrm{Nu}=\alpha \mathrm{d} / \lambda$, де $\lambda-$ коефіцієнт теплопровідності рідини, Вт/(м·К); $\operatorname{Pr}=v / \mathrm{a}$ - число Прандтля, яке характеризує теплофізичні властивості рідини, а - коефіцієнт температуропровідності рідини, м²/c; П $\varepsilon_{\mathrm{i}}$ - добуток поправок на конкретні умови процесу теплообміну. 
Поправка $\varepsilon_{q}=\left(\operatorname{Pr} / \operatorname{Pr}_{c}\right)^{0,25}$ враховує напрям теплового потоку (нагрівання, охолодження) та величину температурного напору між стінкою і рідиною $\left(\mathrm{t}_{\mathrm{c}}-\mathrm{t}\right)$ aбо $\left(\mathrm{T}_{\mathrm{c}}-\mathrm{T}\right)$ ( Т, К - абсолютна температура ).

Вплив числа Прандтля на $\alpha$ для труб і трубних пучків однаковий, він не залежить від величини $\mathrm{Re}, \mathrm{a} \mathrm{m}=0,36(0,36+0,25=0,61)$. Зі зменшенням кута атаки $\varphi$, тобто кута між напрямком потоку рідини і віссю труби $\alpha$ поступово зменшується. Як для поодинокої труби, так і для пучків труб поправку на величину кута атаки (для $\left.\varphi=30 \ldots 90^{\circ}\right)$ з граничною відносною похибкою у $2,3 \%$ можна оцінити за єдиною формулою:

$$
\varepsilon_{\varphi}=(\sin \varphi)^{0,567} .
$$

Наприклад, для $\varphi=30^{\circ}$ одержимо $\varepsilon_{\varphi}=0,675$, а при $\varphi=50^{\circ}-0,860$.

Стосовно обтікання поодинокої труби при $\mathrm{Re}=5 \ldots 10^{3}$ в рівнянні (1) $\mathrm{C}=0,56$; $\mathrm{n}=0,50$ та $\mathrm{m}=0,36$, а якщо $\mathrm{Re}=10^{3} \ldots 2 \cdot 10^{5}$, то $\mathrm{C}=0,28 ; \mathrm{n}=0,60$ та $\mathrm{m}=0,36$.

Коефіцієнт тепловіддачі при обтіканні водою поодинокої труби може бути визначений за формулою:

$$
\alpha=C \lambda \omega^{\mathrm{n}} \mathrm{d}^{\mathrm{n}-1} \nu^{-\mathrm{n}} \operatorname{Pr}^{0,61} \operatorname{Pr}_{\mathrm{c}}^{-0,25} \varepsilon_{\varphi} .
$$

У пучках розміщення труб може бути коридорним і шаховим. Характеристиками пучка $є$ діаметр труб $\mathrm{d}$ та відносні відстані між осями труб по ширині пучка $\mathrm{S}_{1} / \mathrm{d}$ та по його глибині $\mathrm{S}_{2} / \mathrm{d}$. Поправка $\varepsilon_{\mathrm{s}}$ на вплив відносних кроків труб для їх коридорного розміщення:

для шахового розміщення

$$
\varepsilon_{\mathrm{SK}}=\left(\mathrm{S}_{2} / \mathrm{d}\right)^{-0,15} ;
$$

$$
\text { при } \mathrm{S}_{1} / \mathrm{S}_{2}<2 \varepsilon_{\text {sш }}=\left(\mathrm{S}_{1} / \mathrm{S}_{2}\right)^{1 / 6} ; \text { при } \mathrm{S}_{1} / \mathrm{S}_{2} \geq 2 \varepsilon_{\text {sш }}=1,12 \text {. }
$$

Тепловіддача суттєво залежить від початкової турбулентності потоку. Починаючи з третього ряду турбулентність потоку стабілізується. Критеріальні рівняння для $\alpha$ одержані на основі узагальнення експериментальних даних стосовного 3-го і наступних рядів труб пучка. У першому ряду труб тепловіддача дещо менша $\alpha_{1}=0,6 \alpha_{3}$, у другому для шахового пучка $\alpha_{2 ш}=0,7 \alpha_{3}$, для коридорного $\alpha_{2 \kappa}=0,9 \alpha_{3}$.

При визначенні середнього для всього пучка $\bar{\alpha}$ вводиться поправка $\varepsilon_{\mathrm{N}}$, яка враховує кількість рядів труб «n» у пучку. Для коридорного пучка

для шахового

$$
\varepsilon_{\mathrm{N \kappa}}=(\mathrm{n}-0,5) / \mathrm{n} \text {, }
$$

$$
\varepsilon_{\mathrm{N} \amalg}=(\mathrm{n}-0,7) / \mathrm{n} \text {. }
$$

Стосовно коридорного і шахового пучків при $\mathrm{Re}=10^{2} \ldots 10^{3}$ маємо $\mathrm{C}=0,56 \mathrm{i}$ $\mathrm{n}=0,50$ та $\mathrm{m}=0,36$. Коефіцієнт тепловіддачі дорівнює:

$$
\bar{\alpha}_{\mathrm{K}}=\bar{\alpha}_{\mathrm{II}}=\mathrm{C} \lambda \omega^{\mathrm{n}} \mathrm{d}^{\mathrm{n}-1} v^{-\mathrm{n}} \operatorname{Pr}^{0,61} \operatorname{Pr}_{\mathrm{c}}^{-0,25} \varepsilon_{\varphi} \cdot \varepsilon_{\mathrm{S}} \cdot \varepsilon_{\mathrm{N}} .
$$

Коли в коридорному пучку $\operatorname{Re}=10^{3} \ldots 10^{5}$, то $\mathrm{C}=0,22 \mathrm{i} \mathrm{n}=0,650$ та $\mathrm{m}=0,36$. У цьому ж інтервалі чисел Рейнольдса в шаховому пучку $\mathrm{C}=0,40 \mathrm{i} \mathrm{n}=0,6$ та $\mathrm{m}=0,36$.

Розрахунок коефіцієнтів тепловіддачі води розглянемо на прикладах за таких вихідних даних: $\mathrm{t}=60^{\circ} \mathrm{C}, \mathrm{t}_{\mathrm{c}}=110^{\circ} \mathrm{C}, \mathrm{d}=0,020 \mathrm{~m}, \omega=0,5 \mathrm{~m} / \mathrm{c}, \varphi=50^{\circ}$. Треба знайти $\alpha$ для поодинокої труби та для 8-рядних коридорного і шахового пучків при $\mathrm{S}_{1}=2,5 \mathrm{~d}$ та $\mathrm{S}_{2}=2 \mathrm{~d}$.

У рівняння розрахунку коефіцієнтів тепловіддачі входять теплофізичні властивості води [5-7]. Для них стосовно розглядуваного інтервалу температур $0 \ldots 130^{\circ} \mathrm{C}$ запропоновані прості, але досить точні розрахункові формули (гранична відносна похибка в межах одного відсотка). 
Теплопровідність води, Вт/(м·К):

Кінематична в'язкість, м $^{2}$ с:

$$
\lambda=(0,603-28,73 /(\mathrm{t}+100))^{0,5} .
$$

$$
v \cdot 10^{9}=\exp \left(3,629+436,5 / \mathrm{t}_{\mathrm{p}}-5060 / \mathrm{t}_{\mathrm{p}}{ }^{2}\right)^{-1},
$$

де $\mathrm{t}_{\mathrm{p}}=\mathrm{t}+100$.

Числа Прандтля:

Число Рейнольдса:

$$
\operatorname{Pr}=10^{-2} \exp (0,3434-55,92 / \mathrm{T})^{-1} .
$$

$$
\mathrm{Re}=10^{9} \omega \mathrm{d} / \exp (0,2905-42,77 / \mathrm{T})^{-1} .
$$

3a $\mathrm{t}=60^{\circ} \mathrm{C} \lambda=0,650 \mathrm{B \textrm {T }} /(\mathrm{M} \cdot \mathrm{K}), \quad v=477 \cdot 10^{-9} \mathrm{M}^{2} / \mathrm{c}, \quad \operatorname{Pr}=2,98$, $\operatorname{Re}=0,5 \cdot 0,02 / 477 \cdot 10^{9}=2,096 \cdot 10^{4}>10^{3}$. При $\mathrm{t}_{\mathrm{c}}=110^{\circ} \mathrm{C} \operatorname{Pr}_{\mathrm{c}}=1,583$.

При обтіканні водою поодинокої труби за формулою (3):

$\alpha=0,28 \cdot 0,650 \cdot 0,5^{0,6} \cdot 0,02^{-0,4}\left(477 \cdot 10^{-9}\right)^{-0,6} \cdot 2,98^{0,61} \cdot 1,583^{-0,25} \cdot 0,86=5319 \mathrm{BT} /\left(\mathrm{M}^{2} \cdot \mathrm{K}\right)$.

Вплив відносних кроків труб для коридорного пучка (формула 4) $\varepsilon_{\text {sк }}=$ $=(2)^{0,15}=0,901$, а для шахового (формула 5) розміщення $\varepsilon_{\mathrm{sш}}=(2,5 / 2)^{1 / 6}=1,04$. Поправка на кількість рядів труб для коридорного пучка $\varepsilon_{\mathrm{N \kappa}}=(8-0,5) / 8=0,938$ (за формулою 6), а для шахового (формула 7) $\varepsilon_{\text {Nш }}=(8-0,7) / 8=0,912$. За формулою (8) середній коефіцієнт тепловіддачі для 8-рядного коридорного пучка:

$\bar{\alpha}_{\mathrm{K}}=0,22 \cdot 0,65 \cdot 0,5^{0,65} \cdot 0,02^{-0,35}\left(477 \cdot 10^{-9}\right)^{-0,65} \cdot 2,98^{0,61} \cdot 1,583^{-0,25} \cdot 0,86 \cdot 0,901 \cdot 0,938=5809 \mathrm{BT} /$ $/\left(\mathrm{M}^{2} \cdot \mathrm{K}\right)$.

За аналогічною формулою для шахового пучка:

$\bar{\alpha}_{\text {II }}=0,40 \cdot 0,65 \cdot 0,5^{0,6} \cdot 0,02^{-0,4}\left(477 \cdot 10^{-9}\right)^{-0,6} \cdot 2,98^{0,61} \cdot 1,583^{-0,25} \cdot 0,86 \cdot 1,04 \cdot 0,912=7207 \mathrm{BT} /\left(\mathrm{M}^{2} \cdot \mathrm{K}\right)$.

В однакових умовах тепловіддача в шахових пучках інтенсивніша порівняно 3 коридорними, де в проходах між рядами труб утворюються застійні зони.

Результати розрахунків $\alpha$ за запропонованими формулами і розрахунків $\alpha$ через відповідні критеріальні рівняння практично збігаються.

Висновки. Проаналізовано основні варіанти тепловіддачі при поперечному обтіканні водою труб і трубних пучків. Наведено прості і досить точні формули та числові приклади розрахунку коефіцієнтів тепловіддачі без використання таблиць теплофізичних параметрів води і таблиць поправок. Це полегшує та прискорює розрахунки, надає можливість використовувати формули в різноманітних комп'ютерних програмах.

\section{ЛІТЕРАТУРА}

1. Василенко С. М. Основи тепломасообмену: підручник / С. М. Василенко, А. І. Українець, В. В. Олішевський. - К.:НУХТ, 2004. - 250 с.

2. Кутателадзе С. С. Теплопередача и гидродинамическое сопротивление: справочное пособие / С. С. Кутателадзе. - М.: Энергоатомиздат, 1990. — 367 с.

3. Константінов С. М. Теоретичні основи теплотехніки: підручник / С. М. Константінов, Є. М. Панов. - К.: «Золоті ворота», 2012. - 592 с.

4. Беляев Н. М. Основы теплопередачи: учебник / Н. М. Беляев. - К.: Вища шк. Головное изд-во, 1989. - $343 \mathrm{c.}$

5. Теоретические основы теплотехники. Теплотехнический эксперимент: справочник / Под общ. ред. В. А. Григорьева, В. М. Зорина. - М.: Энергоатомиздат, 1988. — 560 с. (Теплоэнергетика и теплотехника: Кн.2).

6. Физические величины: справочник / Под ред. И. С. Григорьева, Е. 3. Мейлихова. - М.: Энергоатомиздат, 1991. - 1232 с.

7. Свойства материалов и веществ: Вода и водяной пар. Вып.1. Таблицы стандартных справочных данных / ВНИЦМВ. М.: Изд-во стандартов, 1990. - 160 с. 


\title{
ТЕПЛООТДАЧА ВОДЫ ПРИ ПОПЕРЕЧНОМ ОБТЕКАНИИ ТРУБ И ТРУБНЫХ ПУЧКОВ
}

\author{
Д. Е. Синат-Радченко, Н. В. Иващенко, С. М. Василенко \\ Национальный университет пищевых технологий
}

На основе обобщения данных по теплофизическим свойствам воды и анализа ее теплоотдачи при поперечном обтекании труб и трубных пучков для интервала температур $0 . .130^{\circ} \mathrm{C}$ и различных условий и режимов движения воды предложен ряд простых, но достаточно точных фрормул (и числовых примеров) относительно расчета коэффрициентов теплоотдачи без использования каких-либо таблиц и интерполяции. Это облегчает и ускоряет инженерные расчеты и дает возможность использовать формулы в различных компьютерных программах.

Ключевые слова: вода, трубы, пучки труб, поперечное обтекание, режимы течения, коэффициент теплоотдачи, поправка. 